\title{
Board 92: MAKER: Developing Compostable Composites: A Multi-disciplinary Approach towards Sustainable Material Adoption
}

\section{Dr. Louise Rosanna Manfredi, Syracuse University}

Dr. Manfredi holds a Ph.D. in Mechanical Engineering (2011) and a BDes in Product Design (2006) from the University of Leeds, UK.

Dr. Manfredi's primary research interest centers on sustainable product development, and how the decisions designers and engineers make affect the environment during the life cycle of these products. She is particularly focused on the development of sustainable/environmentally conscious toolkit which give future designers access to cutting-edge techniques in product development and manufacture.

Louise is also interested in the assessment and development of environmentally conscious materials in the prototyping phase of product development. 


\title{
WIP/MAKER: Developing compostable composites: A multi- disciplinary approach towards sustainable material adoption
}

\begin{abstract}
Engineering design is a human-centric discipline that seeks to produce products, services, and systems that enrich and improve people's lives. Designers can influence the way we feel about ourselves, how we interact with others, and how we feel about the world around us. Conversely, we can create negative effects; most notably, landfill waste. With a burgeoning world population, much attention is focused on how we sustainably use our ever-decreasing supply of materials. This project was framed within the context of low-cost flat-pack furniture, which is typically made from non-biodegradable particleboard. The end-of-life for particleboard is landfill or incineration.
\end{abstract}

The overarching research goal of this project was to determine whether post-consumer paper and a bioplastic binder were suitable for the creation of a more environmentally friendly composite (than its traditional particleboard counterpart) that has future potential to be composted with food waste. Specifically, we aimed to (1) empirically test how this composite performs under standard material testing methods in comparison to a low-density chipboard, (2) determine to what extent these composites can be produced and used without the need for specialist equipment, and (3) begin to investigate the triple bottom line (social, environmental and financial) though various life cycle analysis methods. From the environmental perspective, employing a circular design approach (utilizing waste from other industries, in this case, used paper) the environmental question becomes: can we create a material of 'value' that makes some progress towards reducing manufacturing carbon emission?

The novelty of this research lies in the pairing of mechanical material testing with usability testing with research study participants who might work with novel materials. Undergraduate design students were recruited to evaluate composite material samples for ease of machining and fastening.

\section{Introduction}

\section{A. Designed for landfill}

In our pursuit for sustainable design, we could design products that are easy to disassemble and recycle [1], design products for repair, or more progressively, use materials that are biodegradable to make objects. Objects made from biodegradable materials could be returned to the earth with little effort and may serve us well as we try to change our disposable culture [2]. A notable example that has been successful a mycelium and agricultural waste packaging material company [3]. This business seeks to remove earth-damaging Styrofoam from the packaging industry by using mushroom spore growth through agricultural waste to create a completely compostable material to safely pack expensive products, such as computers, for transportation. Whilst this material is incredibly effective for the industry it has disrupted, it is brittle and would not be suited for repeated and heavy consumer interaction. The introduction of an elastic 
bioplastic binder, rather than a brittle binder such as mycelium, may present opportunities for more robust uses in products that consumers use routinely.

\section{B. Innovation in sustainable materials}

A specific case study for the use of a paper-bioplastic composite that has potential to address aspects of disposable culture is low cost furniture. The rise of inexpensive chipboard flat-pack furniture that we do not feel a strong emotional connection to is ubiquitous. These items are typically designed and priced to suit the 'good enough for now' market category, leaving the consumer with the disposal of materials that cannot be recycled. Broken or discarded furniture can in some instances be repurposed, but access to these collection points can be limited depending on geographical location, or your availability to go to the next product retrieval event in your area. Moreover, particleboard, a common material in such furniture, cannot be recycled or repurposed (unless donated), thus ends life in the incinerator or in landfill. In Syracuse, New York, for example, the resource collection agency does not recycle wooden or particle board furniture and only offers disposal services [4]. Further afield in the United Kingdom, a similar problem exists with furniture going to landfill rather than reuse or repurpose [5].

One potential solution may be for low cost furniture to be made from a biodegradable material so at the end of its life it can be composted alongside vegetable waste, thus eliminating the need for landfill. Even more attractive a proposition would be to adopt a cradle-to-cradle design approach that promotes the use of a non-virgin base material thus given a second life to become something different [6]. Furthermore, pooling useful materials for their next life as a different product ties in to improving the triple bottom line of cost and environmental impact [7]. A bioplastic binder (not an oil-derived polymer) that impregnates post-consumer paper could be a viable material combination. As is many large institutions, Syracuse University produces vast quantities of paper waste which provides an ideal opportunity and ample supplies to experiment with.

The use of bioplastics in design is on the rise [8], but their use is still comparatively low compared to that of oil-based plastics. Brockhaus, Petersen, \& Kersten [9] discuss how we find ourselves at a crossroad in the use of bioplastics in design and that to truly move the use of more sustainable materials forward, a behavioral shift needs to occur, and knowledge of sustainably produced material is crucial. The critical assessment of material properties, the scenarios in which they can used, and appreciating its impact economically and environmentally is essential, especially in undergraduate design and engineering education [10].

\section{Bioplastic composite opportunity and lack of usability research}

Bioplastics are derived from a variety of natural sources; agar, gelatin, starch, and lactic acid [11] and have various mechanical properties that are desirable, and not so desirable. Determining the correct application for these bioplastics is challenging, but there have been successful applications of bioplastics in the single-use product category, such as cups and cutlery from sugar [12], methane gas [13], and food waste [14]. Whilst there are examples of paper [15] or wood fibers [16] being used to reinforce bioplastics, no known study has been found which brings these insights to the manufacturing of consumer goods. Furthermore, there are no known examples of studies which sought to the compare mechanical properties (such as fatigue in 
cyclical loading or fracture when struck) or to human insight through usability metrics (how easy the material is to machine, for example). This work-in-progress research plan aims to bring these fields together to build a stronger picture of how materials can be made and used effectively. This project was set within the timeframe of a 15-week semester (spring 2019) with one undergraduate research assistant from a non-engineering discipline.

\section{Methods}

\section{A. Project aims}

Aim (1). To empirically satisfy 'value', we need to be confident that a composite can perform under stress before it can be promoted as a material that is a better environmental alternative. In the test case of a chair, how the material performs under the load of, for example, a seated adult must be rigorously tested [17]. Also, it must remain structurally sound with hundreds of seating for example, a characteristic that can be simulated in a testing environment through cyclical loading and unloading of a force. It is only after analysis of these results that one can determine whether the composite material is mechanically suitable for use in the given case study, then a comprehensive life cycle analysis can be performed.

Aim (2). To understand the usability characteristics of the material, we need to allow designers to experiment with the material. How well does the composite cut and fasten to create a structure? How might this material be developed to solve a design need?

Aim (3). Data from this study will be analyzed during a life cycle analysis (LCA) and circular economic training course at University College London in May 2019. This training course is designed to help researchers understand tradition LCA techniques and emerging analyses in circular economic modeling. Preliminary reports will be shared at the time of poster presentation.

\section{B. Making composites}

Following the basic formulations outlined by Stevens [11], gelatin, starch, and agar are the primary biopolymers used to create the matrix for the composite. Glycerin or sorbitol is added as a plasticizer to alter the mechanical property of brittleness. An example formulation which we are experimenting with is: 1 tsp biopolymer $+120 \mathrm{ml}$ water $+1 / 2$ tsp plasticizer. The biopolymers which are investigated in this project were gelatin and agar (Table 1), which have different price points and potentially different impacts on the environment. We anticipated that they might have different mechanical properties also.

The bioplastic components were mixed together until dissolved, then heated to 95 degrees centigrade and stirred continuously until no visible lumps are seen. The reinforcement is mixed in, and the composite is then left to cool at room temperature in low humidity, which can take between 12 and 36 hours, depending on the bioplastic viscosity. The departure from the basic formulations will lie in our addition of reinforcement materials to create a composite. For this, we are experimenting with different used paper type (such as copier paper and sketchbook paper) and preparing samples for mechanical testing that have differing pre-processing techniques, such 
as cut strips versus macerated paper to retain fiber length. Table 1 shows the specific ratios used to create the bioplastic matrices.

Table 1. Bioplastic formulae

\begin{tabular}{|l|l|l|l|l|}
\hline Biopolymer & $\begin{array}{l}\text { Biopolymer } \\
\text { (g) }\end{array}$ & Plasticizer & $\begin{array}{l}\text { distilled water } \\
\text { with 1\% } \\
\text { plasticizer }(\mathbf{m l})\end{array}$ & Qualities of bioplastic [11] \\
\hline Gelatin & 12 & Glycerol & 240 & Plexiglas - brittle \\
\hline Gelatin & 4.5 & Glycerol & 240 & $\begin{array}{l}\text { Biowrap - intermediate } \\
\text { flexibility }\end{array}$ \\
\hline Agar & 6 & Glycerol & 240 & Plexiglas - brittle \\
\hline Agar & 3 & Glycerol & 240 & $\begin{array}{l}\text { Biowrap - intermediate } \\
\text { flexibility }\end{array}$ \\
\hline Gelatin & 48 & Glycerol & $240(5 \%$ solution) & Viscose - brittle \\
\hline
\end{tabular}

All samples were combined with $55 \mathrm{~g}$ of cross cut discarded computer paper. The paper was added to the molten bioplastic, and mixed until visually, the paper has absorbed the liquid. Initial samples were made left to cure in a fume hood for 48 hours. Smaller samples of the bioplastics were poured and left to cure also, to capture mass loss through evaporation.

\section{Mechanical testing preparation}

ASTM D638-14 [18] testing standard was selected to evaluate the tensile properties of the composite material. To prepare the samples for mechanical testing, dog bone molds were created using silicone. A positive (the designed dog bone geometry) was 3D printed in resin using an SLA printer. This was then set into silicone to create a dog bone negative, or mold. This open face mold was then used to cast the composite to the correct size for testing.

\section{User testing}

Usability studies were conducted at the School of Design with industrial design students. Participants were solicited via email and given a $\$ 10$ gift for their time. The group of students who routinely work with hand and machine tools will determine how well they worked with the composite. A 7-point Likert scale will be used to characterize the ease of each task from very difficult to very easy. After performing the tasks in Table 2, the participants joined a focus group study to talk about the material and were asked what product uses they think would be applicable for the material.

This data collection captured specific language used to describe working with the new composites in comparison to a low-density particleboard, which is a composite of such, in that phenolic resin is reinforced with wood chippings.

Table 2. Composite manipulation tasks

\begin{tabular}{|l|l|}
\hline Task & Tool type \\
\hline Cut a straight line & Band saw \\
\hline Drill holes & Pillar drill \\
\hline
\end{tabular}


III. Preliminary results

A. bioplastic qualities

Table 3 shows the mass loss when each bioplastic left to cure without reinforcement. Each bioplastic did exhibit the characteristics described by Stevens [11] (table 1 for reference). Unsurprisingly, the solutions with higher perceived viscosity lost less mass when cured. The biowraps had the least biopolymer, thus more plasticizer and produced a thinner film that the other bioplastics. Cloudiness or trapped bubbles were observed in the thicker, more brittle bioplastics.

When combined with the cross-cut paper, the agar bioplastic composites lost more mass when cured (table 4). The flakier texture of the agar composites suggests that the solution was not absorbed into the paper as well as the gelatin composites.

The agar and viscose composites were much more difficult to level after mixing. The uneven surface finish indicates that the composite did not self-level as it cured.

Table 3. Initial bioplastic pours. Decrease in mass when fully cured was captured, in addition to experimental observations.

\begin{tabular}{|l|l|l|}
\hline Bioplastic & $\begin{array}{l}\text { Mass loss } \\
\text { when } \\
\text { cured (\%) }\end{array}$ & Experimental observations \\
\hline $\begin{array}{l}\text { Plexiglas } \\
\text { (gelatin) }\end{array}$ & 92.07 & Thin consistency when heated. Dried flat. Visible bubbles. \\
\hline $\begin{array}{l}\text { Biowrap } \\
\text { (gelatin) }\end{array}$ & 95.19 & $\begin{array}{l}\text { Thin consistency when heated, last one to fully cure. Dried flat. } \\
\text { No visible bubbles. }\end{array}$ \\
\hline $\begin{array}{l}\text { Plexiglas } \\
\text { (agar) }\end{array}$ & 92.49 & Cloudy solution. Did not dry flat, nor optically clear. \\
\hline $\begin{array}{l}\text { Biowrap } \\
\text { (agar) }\end{array}$ & 97.02 & $\begin{array}{l}\text { Less cloudy than agar Plexiglas. Thicker heated solution than } \\
\text { gelatin biowrap. Dried flat. No visible bubbles. }\end{array}$ \\
\hline $\begin{array}{l}\text { Viscose } \\
\text { (gelatin) }\end{array}$ & 68.17 & $\begin{array}{l}\text { Thick consistency that started setting as soon as it was poured. } \\
\text { Dried with more visible bubbles. }\end{array}$ \\
\hline
\end{tabular}

Table 4. First round composites. Decreased mass when fully cured was captures in addition to experimental observations and cured material observations.

\begin{tabular}{|l|l|l|l|}
\hline Bioplastic & $\begin{array}{l}\text { Mass loss } \\
\text { when } \\
\text { cured (\%) }\end{array}$ & Experimental observations & $\begin{array}{l}\text { Cured material } \\
\text { observations }\end{array}$ \\
\hline $\begin{array}{l}\text { Plexiglas } \\
\text { (gelatin) }\end{array}$ & 63.68 & $\begin{array}{l}\text { Solution absorbed in to paper } \\
\text { quickly. Easy to level the surface. }\end{array}$ & $\begin{array}{l}\text { Dried relatively flat, with } \\
\text { no visible lifting off the } \\
\text { curing surface. }\end{array}$ \\
\hline $\begin{array}{l}\text { Biowrap } \\
\text { (gelatin) }\end{array}$ & 71.95 & Solution was incorporated quickly. & $\begin{array}{l}\text { Bottom of sample has } \\
\text { sheen, unlike to top which } \\
\text { is matte in appearance. }\end{array}$ \\
\hline
\end{tabular}




\begin{tabular}{|l|l|l|l|}
\hline $\begin{array}{l}\text { Plexiglas } \\
\text { (agar) }\end{array}$ & 77.24 & $\begin{array}{l}\text { Gel-like consistency that settled on } \\
\text { top of the paper. Needed thorough } \\
\text { mixing with paper to achieve even } \\
\text { distribution. }\end{array}$ & $\begin{array}{l}\text { Concave warping of } \\
\text { sample. Uneven top and } \\
\text { bottom surfaces. }\end{array}$ \\
\hline $\begin{array}{l}\text { Biowrap } \\
\text { (agar) }\end{array}$ & 78.14 & $\begin{array}{l}\text { Less viscous than agar Plexiglas, } \\
\text { yet still consistency that settled on } \\
\text { top of the paper. Needed thorough } \\
\text { mixing with paper to achieve even } \\
\text { distribution. }\end{array}$ & $\begin{array}{l}\text { Bottom of sample has } \\
\text { very slight sheen, unlike } \\
\text { to top which is matte in } \\
\text { appearance. }\end{array}$ \\
\hline $\begin{array}{l}\text { Viscose } \\
\text { (gelatin) }\end{array}$ & 46.02 & $\begin{array}{l}\text { Most difficult to mix in paper and } \\
\text { level the mix. }\end{array}$ & $\begin{array}{l}\text { Some warping in the dried } \\
\text { sample. Uneven top } \\
\text { surface. }\end{array}$ \\
\hline
\end{tabular}

\section{B. Cutting and drilling insight}

Cutting and drilling insights can be seen in table 5. Call composites cut through on the band saw without fracturing. Blade teeth marks can be seen on the samples with higher gelatin content (figure 1). Cutting through the sample allowed us to see air pockets and unmixed reinforcement which as apparent in the agar composites and the gelatin biowrap. Drilling is shown in figure 2, using a light table to illuminate the holes. Initial observation of the images show that a cleaner hole was achieved in the gelatin Plexiglas with fewer burrs than the other samples. Descriptors from preliminary user testing (table 5) suggests that the gelatin Plexiglas felt 'cleaner' to cut and drill through.

Table 5. Preliminary insights when cutting and drill each material

\begin{tabular}{|l|l|l|}
\hline Bioplastic & Cutting descriptors & Drilling descriptors \\
\hline Plexiglas (gelatin) & Solid clean cut. Some resistance. & $\begin{array}{l}\text { Clean drill through. Little force } \\
\text { needed to drill through. Wasn't sure } \\
\text { when the bit had pierced through. }\end{array}$ \\
\hline Biowrap (gelatin) & $\begin{array}{l}\text { Higher pitch cutting noise, felt } \\
\text { very light. Little blade resistance. }\end{array}$ & Cut was crisp - seemed dry? \\
\hline Plexiglas (agar) & $\begin{array}{l}\text { Higher pitch cutting noise. Little } \\
\text { force needed to push sample } \\
\text { through the blade. }\end{array}$ & $\begin{array}{l}\text { Couldn't feel when it pierced } \\
\text { through. Seemed sturdy. }\end{array}$ \\
\hline Biowrap (agar) & $\begin{array}{l}\text { Higher pitch cutting noise, sample } \\
\text { vibrated when cutting. Felt loose } \\
\text { and fragile. Expected it to fall } \\
\text { apart mid cut. }\end{array}$ & $\begin{array}{l}\text { Tried to climb the drill bit. Felt } \\
\text { fragile. }\end{array}$ \\
\hline Viscose (gelatin) & $\begin{array}{l}\text { More force needed to push through } \\
\text { the sample through the blade }\end{array}$ & $\begin{array}{l}\text { Dense cut with little give when cut } \\
\text { through to the wooden rest below. }\end{array}$ \\
\hline
\end{tabular}




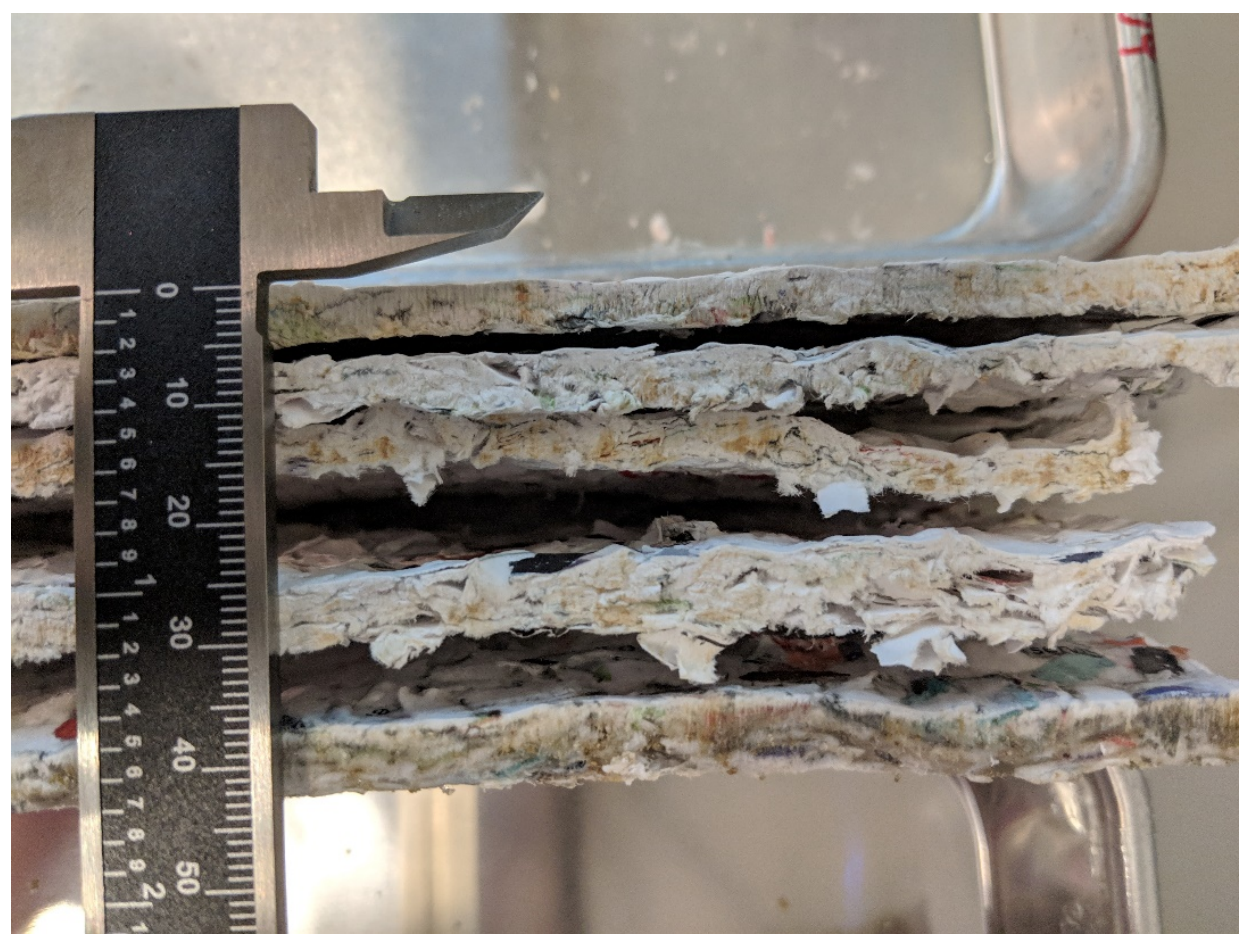

Figure 1. Samples cut with wood blade on a band saw. Top to bottom: gelatin Plexiglas, gelatin biowrap, agar Plexiglas, agar biowrap, gelatin viscose.
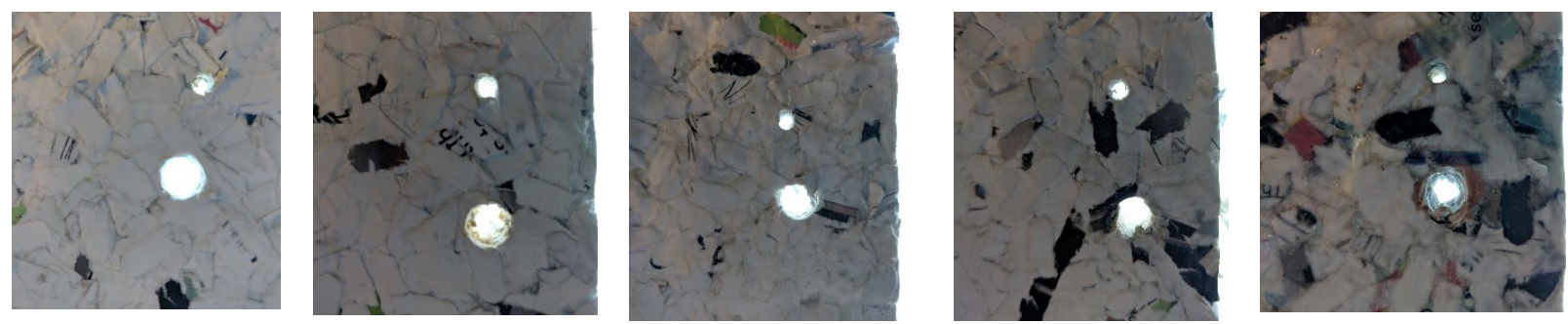

Figure 2. Holes drilled through the samples: 1/8 and 1/4 inch. Left to right: gelatin Plexiglas, gelatin biowrap, agar Plexiglas, agar biowrap, gelatin viscose.

\section{Work in progress}

This is a work in progress investigation that has been hampered by delayed grant announcements. As such, our work progress has been affected, however, and we are strategizing ways to produce even and consistent dogbones for standards driven testing. Sample creation methodology was to use non-specialist equipment to create a more environmentally composite that might mimic o low density particleboard. At present, leaving the composites to cure in open molds results in a fair amount of mass reduction. Whilst this is not necessarily negative, controlling the even absorption of the matrix and reinforcement is problematic. This results in air pockets, some pockets of uneven matrix distribution, and perhaps contributes to some poor surface finish. Strategies to achieve uniform thickness and a smooth surface finish will be important to mechanical testing data collection.

More results will be shared on the poster that accompanies this paper, including initial tensile and three-point bend testing data, plus more user insight from working with the materials. 
Works Cited

[1] M. Germani, M. Mandolino, M. Marconi and M. Rossi, "An approach to analytically evaluate the product dissasemblability during the design process," Procedia CIRP, pp. 336$341,2014$.

[2] A. Coskun, J. Zimmerman and C. Erbug, "Promoting sustainability through behavior change: A review," Design Studies, pp. 183-204, 2015.

[3] Ecovative, "The Mycelium Biofabrication Platform," 29 June 2018. [Online]. Available: https://ecovativedesign.com/home.

[4] OCCRA, "How do I get rid of: Furniture," 13 Spetember 2018. [Online]. Available: http://ocrra.org/how-do-i-get-rid-of/furniture/.

[5] F. Granström, Socio-economic evaluation: An exploratory case study of a community waste, Cranfield: Cranfield University, 2006.

[6] M. Braungart and W. McDonough, Cradle to Cradle: Remaking the Way We Make Things, North Point Press, 2002.

[7] M. Braungart, W. McDonugh and A. Bollinger, "Cradle-to-cradle design: creating healthy emissions - a strategy for eco-effective product and system design," Journal of Cleaner Production, pp. 1337-1348, 2007.

[8] J. Conciatore, "From tea bags to Miatas, bioplastics are on the," 3 March 2015. [Online]. Available: https://www.nsf.gov/discoveries/disc_summ.jsp?cntn_id=134326.

[9] S. Brockhaus, M. Petersen and W. Kersten, "A cross roads for bioplastics: exploring product developers' challenges to move beyond petroleum-based plastics," Journal of Cleaner Production., pp. 84-95, 2016.

[10] E. Gerber, A. McKenna, P. Hirsch and C. Yarnoff, "Learning to waste and wasting to learn? How to use cradle to creadle principles to improve the teaching of design," International Journal of Enigneering Education, pp. 314-232, 2010.

[11] E. S. Stevens, Green plastics: An introduction to the new science of biodegradable plastics, Princeton and Oxford: Princeton University Press, 2002.

[12] G. L. Gregory, G. Kociok-Kohn and A. Buchard, "Polymers from sugrds and CO2: Ringopening polymerization and copolymerisation of cyclic carbonates derived from 2-deoxyD-ribose," Polymer Chemistry, pp. 2093-2104, 2017.

[13] "Mango Materials," 2 April 2018. [Online]. Available: www.mangomaterials.com.

[14] "Full Cyle Bioplastics," 2 April 2018. [Online]. Available: http://fullcyclebioplastics.com/.

[15] R. Bharddwaj, A. K. Mohanty, L. T. Drzal, F. Pourboghrat and M. Misra, "Renewable resource-based green composites from recycled cellulose friber and poly bioplastic," Biomacromolecules, pp. 2044-2051, 2006.

[16] S. Singh and A. K. Mohanty, "Wood fiber reinforced bacterial bioplastc composites: Fabrication and performance evaluation," Composites Science and Technology, pp. 17531763, 2007.

[17] ASTM, "D7774-17. Standard Test Method for Flexural Fatigue Properties of Plastics," ASTM International, Conschohocken, PA, 2017. 
[18] ASTM, "D638-14 Standard Test Method of Tensile Properties of Plastics.," 2014. [Online]. Available: https://doi.org/10.1520/D0638-14. 